\title{
Challenges for scaling up conservation
}

\author{
A grand plan to devote half the planet to nature could create conflicts with farming. A global analysis locates the \\ countries and ecoregions where scaling up habitat protection will be most difficult.
}

\author{
Benjamin T. Phalan
}

I alf-Earth is a bold, controversial idea, a proposal that humanity set aside $50 \%$ of the Earth's surface for nature ${ }^{1}$. That's far more than the $17 \%$ most global leaders have committed to, but closer to what conservation biologists say is needed to sustain wild species ${ }^{2}$. The Half-Earth proposal has prompted praise, criticism and questions ${ }^{3,4}$. How achievable is it, and what would it mean for farming and food? Writing in this issue of Nature Sustainability, Mehrabi and colleagues ${ }^{5}$ analyse the potential effects of this proposal on global crop production.

At the planetary scale, Half-Earth seems achievable. Some 12\% of the Earth's land is used for crops, another $22 \%$ for pasture and $3 \%$ for cities $^{6,7}$. Most of the rest - more than half the Earth - supports relatively natural ecosystems, from ice sheets to tropical forests. It's important to consider not only how much land is protected but also what and where ${ }^{8}$. To cover all species, habitats must be protected across different countries and ecoregions, meaning areas of land or sea with characteristic ecosystems.

Protecting half of each country or ecoregion is more challenging. Mehrabi et al. estimate that if half of each country were protected, starting with the least productive land, $10 \%$ of global cropland and $75 \%$ of global pasture would be affected ${ }^{5}$. The overlaps would be even greater if the aim were to protect half of each ecoregion. Although the impacts on food production would be relatively small - up to $3 \%$ in the more realistic scenarios - the impacts on some of Earth's poorest people could be severe. Governments have long oppressed, dispossessed and displaced the human inhabitants of protected areas, and a massive scaling up of conservation efforts could increase such social conflict ${ }^{4}$.

Fears about the implications of Half-Earth have been fuelled by uncertainty over how it might be achieved. Will the idea prompt innovative conservation efforts that empower local and indigenous peoples or a doubling-down on fortress conservation while ignoring the root causes of biodiversity

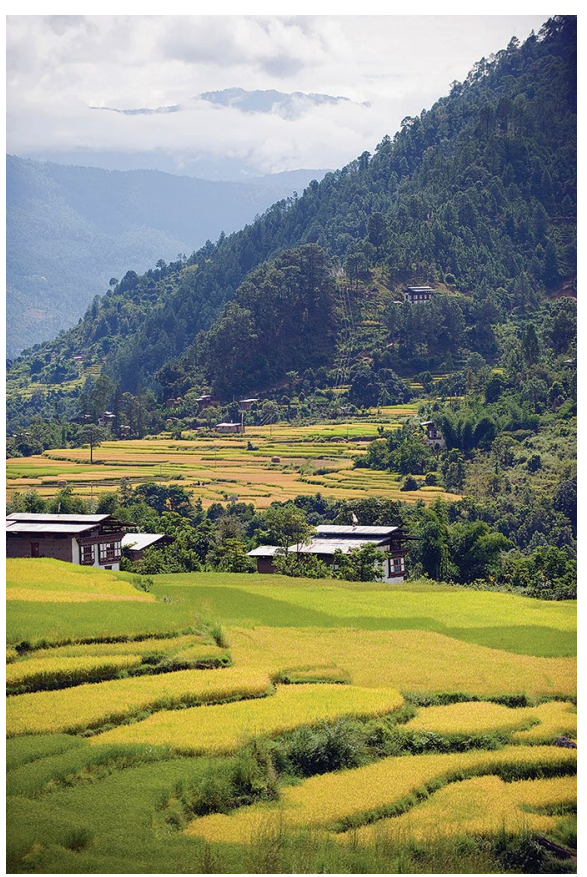

Landscape in Bhutan, a country with more than $50 \%$ of its land under some form of protection, as mandated by its constitution. In this issue, Mehrabi et al. analyse how scaling up conservation to this level in other countries and ecoregions could affect crop production. Credit: The Photolibrary Wales/Alamy Stock Photo

loss? Analyses like those of Mehrabi et al. clarify the scale of the challenge and identify regions where special care is needed to navigate conflicts - as with farming in India, Indonesia and West Africa.

Their results highlight the importance of balancing livestock grazing and conservation. Pasture is declining globally and much of it is unproductive: rewilding the least productive $50 \%$ of grazed lands in the United States would reduce beef production by only $2 \%$ (ref. ${ }^{10}$ ). While livestock cause serious damage to some ecosystems, in others combining extensive grazing with conservation can reduce conflict.
The results of Mehrabi et al. reinforce the conclusion that, in some places, protecting $50 \%$ is unrealistic ${ }^{11}$. Half-Earth is better seen as a visionary rallying cry than as a rigid, universal target. At the same time, three countries and $\sim 100$ ecoregions have already protected half or more of their land ${ }^{11}$. Namibia, Nepal and Bhutan have done so in part by involving local people. More can be achieved by following their example and by recognizing and working with indigenous peoples, who manage $25 \%$ of the world's land ${ }^{12}$.

The analysis by Mehrabi et al. is a first step. It should be refined with more-recent and fine-grained data as they become available and with analyses of the potential to reduce conflicts by increasing yields in established croplands ${ }^{13}$. Its value is in starting to quantify one of the key challenges faced if the Half-Earth concept gains traction: finding space for farms and farmers as well as for native ecosystems and wild species.

\section{Benjamin T. Phalan ${ }^{1,2}$ \\ ${ }^{1}$ Instituto de Biologia, Universidade Federal da Bahia, Salvador, Bahia, Brazil. ${ }^{2}$ Department of Forest Ecosystems and Society, College of Forestry, Oregon State University, Corvallis, OR, USA. e-mail:phalanb@oregonstate.edu}

Published online: 14 August 2018 https://doi.org/10.1038/s41893-018-0122-0

\footnotetext{
References

1. Wilson, E. O. Half-Earth: Our Planet's Fight for Life (Liveright, New York, 2016).

2. Svancara, L. K. et al. BioScience 55, 989-995 (2005)

3. Kopnina, H. Biol. Conserv. 203, 176-185 (2016).

4. Büscher, B. et al. Oryx 51, 407-410 (2017).

5. Mehrabi, Z., Ellis, E. C. \& Ramankutty, N. Nat. Sustain. https:// doi.org/10.1038/s41893-018-0119-8 (2018).

6. Ramankutty, N. et al. Global Biogeochem. Cycles 22, GB1003 (2008).

7. Liu, Z. et al. Landscape Ecol. 29, 763-771 (2014).

8. Barnes, M. D., Glew, L., Wyborn, C. \& Craigie, I. D. Nat. Ecol. Evol. 2, 759-762 (2018).

9. Poore, J. Back to the wild: How nature is reclaiming farmland. New Scientist (9 August 2017).

10. Eshel, G. et al. Nat. Ecol. Evol. 2, 81-85 (2018).

11. Dinerstein, E. et al. BioScience 67, 534-545 (2017).

12. Garnett, S. T. et al. Nat. Sustain. 1, 369-374 (2018).

13. Balmford, A. P. \& Green, R. Nature 552, 175 (2017).
} 